\title{
Effects of Exothermic/Endothermic Chemical Reactions with Arrhenius Activation Energy on MHD Free Convection and Mass Transfer Flow in Presence of Thermal Radiation
}

\author{
Kh. Abdul Maleque \\ Department of Mathematics, American International University-Bangladesh, House-23, 17, Kamal Ataturk Avenue, \\ Banani, Dhaka 1213, Bangladesh \\ Correspondence should be addressed to Kh. Abdul Maleque; maleque@aiub.edu
}

Received 8 March 2013; Accepted 24 May 2013

Academic Editor: Felix Sharipov

Copyright ( $2013 \mathrm{Kh}$. Abdul Maleque. This is an open access article distributed under the Creative Commons Attribution License, which permits unrestricted use, distribution, and reproduction in any medium, provided the original work is properly cited.

\begin{abstract}
A local similarity solution of unsteady MHD natural convection heat and mass transfer boundary layer flow past a flat porous plate within the presence of thermal radiation is investigated. The effects of exothermic and endothermic chemical reactions with Arrhenius activation energy on the velocity, temperature, and concentration are also studied in this paper. The governing partial differential equations are reduced to ordinary differential equations by introducing locally similarity transformation (Maleque (2010)). Numerical solutions to the reduced nonlinear similarity equations are then obtained by adopting Runge-Kutta and shooting methods using the Nachtsheim-Swigert iteration technique. The results of the numerical solution are obtained for both steady and unsteady cases then presented graphically in the form of velocity, temperature, and concentration profiles. Comparison has been made for steady flow $(A=0)$ and shows excellent agreement with Bestman (1990), hence encouragement for the use of the present computations.
\end{abstract}

\section{Introduction}

In free convection boundary layer flows with simultaneous heat mass transfer, one important criteria that is generally not encountered is the species chemical reactions with finite Arrhenius activation energy. The modified Arrhenius law (IUPAC Goldbook definition of modified Arrhenius equation) is usually of the form (Tencer et al. [1])

$$
K=B\left(\frac{T}{T_{\infty}}\right)^{n} \exp \left[\frac{-E_{a}}{k T}\right]
$$

where $K$ is the rate constant of chemical reaction and $B$ that is the preexponential factor simply prefactor (constant) is based on the fact that increasing the temperature frequently causes a marked increase in the rate of reactions. $E_{a}$ is the activation energy, and $k=8.61 \times 10^{-5} \mathrm{eV} / \mathrm{K}$ is the Boltzmann constant which is the physical constant relating energy at the individual particle level with temperature observed at the collective or bulk level.
In areas such as geothermal or oil reservoir engineering, the prvious phenomenon is usually applicable. Apart from experimental works in these areas, it is also important to make some theoretical efforts to predict the effects of the activation energy in flows mentioned above. But in this regard very few theoretical works are available in the literature. The reason is that the chemical reaction processes involved in the system are quite complex and generally the mass transfer equation that is required for all the reactions involved also becomes complex. Theoretically, such an equation is rather impossible to tackle. Form chemical kinetic viewpoint this is a very difficult problem, but if the reaction is restricted to binary type, a lot of progress can be made. The thermomechanical balance equations for a mixture of general materials were first formulated by Truesdell [2]. Thereafter Mills [3] and Beevers and Craine [4] have obtained some exact solutions for the boundary layer flow of a binary mixture of incompressible Newtonian fluids. Several problems relating to the mechanics of oil and water emulsions, particularly with regard to applications in lubrication practice, have been 
considered within the context of a binary mixture theory by Al-Sharif et al. [5] and Wang et al. [6].

A simple model involving binary reaction was studied by Bestman [7]. He considered the motion through the plate to be large which enabled him to obtain analytical solutions (subject to same restrictions) for various values of activation energy by employing the perturbation technique proposed by Singh and Dikshit [8]. Bestman [9] and Alabraba et al. [10] took into account the effect of the Arrhenius activation energy under the different physical conditions. Recently Kandasamy et al. [11] studied the combined effects of chemical reaction, heat and mass transfer along a wedge with heat source and concentration in the presence of suction or injection. Their result shows that the flow field is influenced appreciably by chemical reaction, heat source, and suction or injection at the wall of the wedge. Recently Makinde et al. $[12,13]$ studied the problems of unsteady convection with chemical reaction and radiative heat transfer past a flat porous plate moving through a binary mixture in an optically thin environment. More recently Abdul Maleque $[14,15]$ investigated the similarity solution on unsteady incompressible fluid flow with binary chemical reactions and activation energy. In the present paper, we investigate a numerical solution of unsteady Mhd natural convection heat and mass transfer boundary layer flow past a flat porous plate taking into account the effect of Arrhenius activation energy with exothermic/endothermic chemical reactions and thermal radiation. This problem is an extension work studied by Abdul Maleque [16].

\section{Governing Equations}

We consider the boundary wall to be of infinite extend, so that all quantities are homogeneous in $x$, and hence all derivatives with respect to $x$ are neglected. The $x$-axis is taken along the plate, and $y$-axis is perpendicular to the plate. Assume that a uniform magnetic field $B_{0}$ is applied perpendicular to the plate and the plate is moving with uniform velocity $U_{o}$ in its own plane. In presence of exothermic/endothermic binary chemical reaction with Arrhenius activation energy, a uniform magnetic field and thermal radiation thus the governing equations are

$$
\begin{gathered}
\frac{\partial v}{\partial y}=0, \\
\frac{\partial u}{\partial t}+v \frac{\partial u}{\partial y}=v \frac{\partial^{2} u}{\partial y^{2}}+g \beta_{1}\left(T-T_{\infty}\right) \\
+g \beta_{2}\left(C-C_{\infty}\right)-\frac{\sigma B_{0}^{2}}{\rho} u, \\
\rho c_{p}\left(\frac{\partial T}{\partial t}+v \frac{\partial T}{\partial y}\right)=\kappa \frac{\partial^{2} T}{\partial y^{2}}+\beta k_{r}^{2}\left(\frac{T}{T_{\infty}}\right)^{n} \\
\times \exp \left[\frac{-E_{a}}{k T}\right]\left(C-C_{\infty}\right)-\frac{\partial q_{r}}{\partial y},
\end{gathered}
$$

$$
\frac{\partial C}{\partial t}+v \frac{\partial C}{\partial y}=D_{m} \frac{\partial^{2} C}{\partial y^{2}}-k_{r}^{2}\left(\frac{T}{T_{\infty}}\right)^{n} \exp \left[\frac{-E_{a}}{k T}\right]\left(C-C_{\infty}\right) .
$$

The boundary conditions of previous system are

$$
\begin{gathered}
u=U_{0}, \quad v=v(t), \quad T=T_{w}, \quad C=C_{w} \\
\text { at } y=0, t>0, \\
u=0, \quad T \longrightarrow T_{\infty}, \quad C \longrightarrow C_{\infty} \quad \text { at } y=\infty, t>0,
\end{gathered}
$$

where $(u, v)$ is the velocity vector, $T$ is the temperature, Cis the concentration of the fluid, $\mu$ is the fluid viscosity, $\sigma$ is the electrical conductivity, $v$ is the kinematic coefficient of viscosity, $\beta_{1}$ and $\beta_{2}$ are the coefficients of volume expansions for temperature and concentration, respectively, $\kappa$ is the heat diffusivity coefficient, $c_{p}$ is the specific heat at constant pressure, $D_{m}$ is the coefficient of mass diffusivity, $k_{r}^{2}$ is the chemical reaction rate constant, $\beta(= \pm 1)$ is exothermic/endothermic parameter, and $\left(T / T_{\infty}\right)^{n} \exp \left[-E_{a} / k T\right]$ is the Arrhenius function where $n$ is a unit less constant exponent fitted rate constants typically lie in the range $-1<n<1$.

The radiative heat flux $q_{r}$ is described by Roseland approximation such that

$$
q_{r}=-\frac{4 \sigma_{1}}{3 k_{1}} \frac{\partial T^{4}}{\partial y}
$$

where $\sigma_{1}$ and $k_{1}$ are the Stefan Boltzmann constant and mean absorption coefficient, respectively. Following Makinde and Olanrewaju [13], we assume that the temperature differences within the flow are sufficiently small, so that the $T^{n}$ can be expressed as a linear function. By using Taylor's series, we expand $T^{n}$ about the free stream temperature $T_{\infty}$ and neglecting higher order terms. This result of the following approximation:

$$
T^{n} \approx(1-n) T_{\infty}^{n}+n T_{\infty}^{n-1} T .
$$

Using (9), we have

$$
\begin{gathered}
\frac{\partial q_{r}}{\partial y}=-\frac{4 \sigma_{1}}{3 k_{1}} \frac{\partial^{2} T^{4}}{\partial y^{2}} \approx-\frac{16 T_{\infty}^{3} \sigma_{1}}{3 k_{1}} \frac{\partial^{2} T}{\partial y^{2}}, \\
\left(\frac{T}{T_{\infty}}\right)^{n} \approx(1-n)+n \frac{T}{T_{\infty}} .
\end{gathered}
$$

\section{Mathematical Formulations}

In order to solve the governing equations (2) to (5) under the boundary conditions (6), we adopt the well-defined similarity technique to obtain the similarity solutions. For this purpose the following nondimensional variables are now introduced:

$$
\begin{aligned}
\eta=\frac{y}{\delta(t)}, & \frac{u}{U_{0}}=f(\eta), \\
\frac{T-T_{\infty}}{T_{w}-T_{\infty}}=\theta(\eta), & \frac{C-C_{\infty}}{C_{w}-C_{\infty}}=\phi(\eta) .
\end{aligned}
$$


From the equation of continuity (3), we have

$$
v(t)=-\frac{v_{0} v}{\delta(t)}
$$

where $v_{0}$ is the dimensionless suction/injection velocity at the plate, $v_{0}>0$ corresponds to suction, and $v_{0}<0$ corresponds to injection.

Introducing (9), (10), the dimensionless quantities from (11) and $v$ from (12) in (4), (5), and (6), we finally obtain the nonlinear ordinary differential equations as

$$
\begin{aligned}
& f^{\prime \prime}+\left(\eta \frac{\delta \delta^{\prime}}{v}+v_{0}\right) f^{\prime}-M f+G_{0} \gamma \theta+G_{m} \phi=0 \\
& \theta^{\prime \prime}+\left(\frac{P_{r}}{1+N}\right)\left[\left(\eta \frac{\delta \delta^{\prime}}{v}+v_{0}\right) \theta^{\prime}\right. \\
&\left.+\beta \lambda^{2}(1+n \gamma \theta) \exp \left(-\frac{E}{1+\gamma \theta}\right) \phi\right]=0
\end{aligned}
$$$$
\begin{aligned}
S_{c}^{-1} \phi^{\prime \prime} & +\left(\eta \frac{\delta \delta^{\prime}}{v}+v_{0}\right) \phi^{\prime} \\
& -\lambda^{2}(1+n \gamma \theta) \exp \left(-\frac{E}{1+\gamma \theta}\right) \phi=0 .
\end{aligned}
$$

Here, Grashof number $G_{r}=G_{0} \gamma=\left(g \beta T_{\infty} \delta^{2} / v U_{0}\right) \gamma$; the temperature relative parameter $\gamma=\left(T_{w}-T_{\infty}\right) / T_{\infty}$.

Modified (Solutal) Grashof number $G_{m}=g \beta^{*}\left(C_{w}-\right.$ $\left.C_{\infty}\right) \delta^{2} / v U_{0}$; Prandtl number $P_{r}=\rho v c_{p} / \kappa$; magnetic interaction parameter $M=\sigma \delta^{2} B_{0}^{2} / \mu$; schmidt number $S_{c}=v / D_{M}$; the nondimensional activation energy $E=E_{a} / k\left(T_{w}-T_{\infty}\right)$; the dimensionless chemical reaction rate constant $\lambda^{2}=$ $k_{r}^{2} \delta^{2} / v$; radiation parameter $N=16 \sigma_{1} T_{\infty}^{3} / 3 \kappa k_{1}$.

Equations from (13) to (15) are similar except for the term $\delta \delta^{\prime} / v$, where time $t$ appears explicitly. Thus the similarity condition requires that $\delta \delta^{\prime} / v$ must be a constant quantity. Hence following Abdul Maleque [17], one can try a class of solutions of (13) to (15) by assuming that

$$
\frac{\delta \delta^{\prime}}{v}=A \text { (constant) }
$$

From (16), we have

$$
\delta(t)=\sqrt{2 A v t+L^{2}}
$$

where the constant of integration $L$ is determined through the condition that $\delta=L$ when $t=0$. Here $A=0$ implies that $\delta=$ $L$ represents the length scale for steady flow and $A \neq 0$, that is, $\delta$ represents the length scale for unsteady flow. Since $\delta$ is a scaling factor as well as similarity parameter, any other values of $A$ in (13) would not change the nature of the solution except that the scale would be different. Finally introducing (16) in
(13) to (15), respectively, we have the following dimensionless nonlinear ordinary differential equations:

$$
\begin{aligned}
f^{\prime \prime}+\left(A \eta+v_{0}\right) f^{\prime}-M f+G_{0} \gamma \theta+G_{m} \phi=0 \\
\theta^{\prime \prime}+\left(\frac{P_{r}}{1+N}\right)\left[\left(A \eta+v_{0}\right) \theta^{\prime}\right. \\
\left.+\beta \lambda^{2}(1+n \gamma \theta) \exp \left(-\frac{E}{1+\gamma \theta}\right) \phi\right]=0
\end{aligned}
$$

$$
S_{c}^{-1} \phi^{\prime \prime}+\left(A \eta+v_{0}\right) \phi^{\prime}-\lambda^{2}(1+n \gamma \theta) \exp \left(-\frac{E}{1+\gamma \theta}\right) \phi=0
$$

The boundary conditions equation (4) becomes

$$
\begin{gathered}
f(0)=1, \quad \theta(0)=1, \quad \phi(0)=1, \\
f(\infty)=0, \quad \theta(\infty)=0, \quad \phi(\infty)=0 .
\end{gathered}
$$

In all over equations primes denote the differentiation with respect to $\eta$. Equations from (18)-(20) are solved numerically under the boundary conditions (21) using Nachtsheim-Swigert iteration technique.

\section{Numerical Solutions}

Equations (18)-(20) are solved numerically under the boundary conditions (21) using Nachtsheim-Swigert [18] iteration technique. In (21), there are three asymptotic boundary conditions and hence follow three unknown surface conditions $f^{\prime}(0), \theta^{\prime}(0)$, and $\phi^{\prime}(0)$. Within the context of the initial-value method and the Nachtsheim-Swigert iteration technique the outer boundary conditions may be functionally represented by the first-order Taylor's series as

$$
\begin{aligned}
f\left(\eta_{\max }\right) & =f(X, Y, Z) \\
& =f_{c}\left(\eta_{\max }\right)+\Delta X f_{X}+\Delta Y f_{Y}+\Delta Z f_{Z}=\delta_{1}, \\
\theta\left(\eta_{\max }\right) & =\theta(X, Y, Z) \\
& =\theta_{c}\left(\eta_{\max }\right)+\Delta X \theta_{X}+\Delta Y \theta_{Y}+\Delta Z \theta_{Z}=\delta_{2}, \\
\phi\left(\eta_{\max }\right) & =\phi(X, Y, Z) \\
& =\phi_{c}\left(\eta_{\max }\right)+\Delta X \phi_{X}+\Delta Y \phi_{Y}+\Delta Z \phi_{Z}=\delta_{3},
\end{aligned}
$$

with the asymptotic convergence criteria given by

$$
\begin{aligned}
f^{\prime}\left(\eta_{\max }\right) & =f^{\prime}(X, Y, Z) \\
& =f_{c}^{\prime}\left(\eta_{\max }\right)+\Delta X f_{X}^{\prime}+\Delta Y f_{Y}^{\prime}+\Delta Z f_{Z}^{\prime}=\delta_{4}, \\
\theta^{\prime}\left(\eta_{\max }\right) & =\theta^{\prime}(X, Y, Z) \\
& =\theta_{c}^{\prime}\left(\eta_{\max }\right)+\Delta X \theta_{X}^{\prime}+\Delta Y \theta_{Y}^{\prime}+\Delta Z \theta_{Z}^{\prime}=\delta_{5}, \\
\phi^{\prime}\left(\eta_{\max }\right) & =\phi^{\prime}(X, Y, Z) \\
& =\phi_{c}^{\prime}\left(\eta_{\max }\right)+\Delta X \phi_{X}^{\prime}+\Delta Y \phi_{Y}^{\prime}+\Delta Z \phi_{Z}^{\prime}=\delta_{6},
\end{aligned}
$$




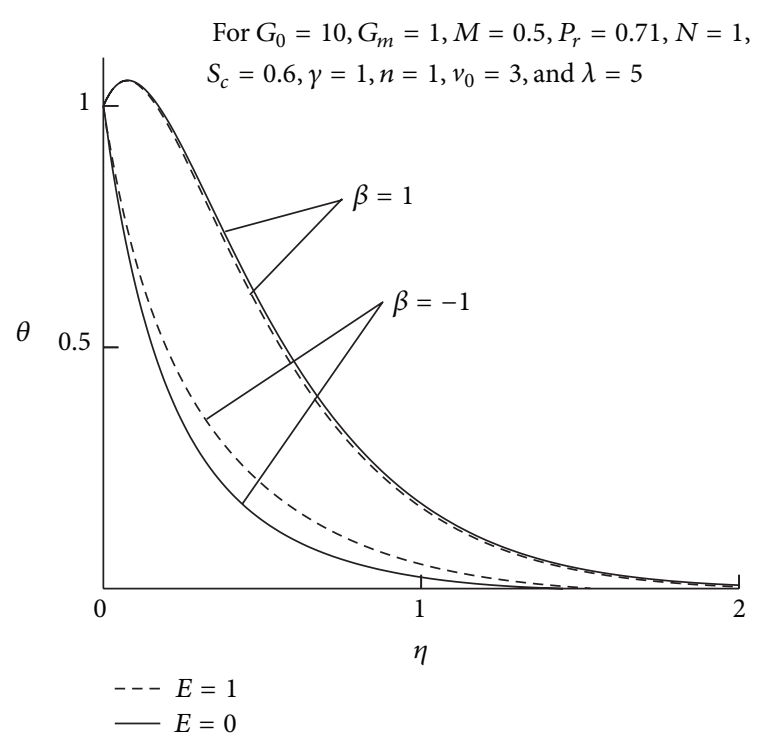

Figure 1: Effects of $\beta$ and $E$ on temperature profiles.

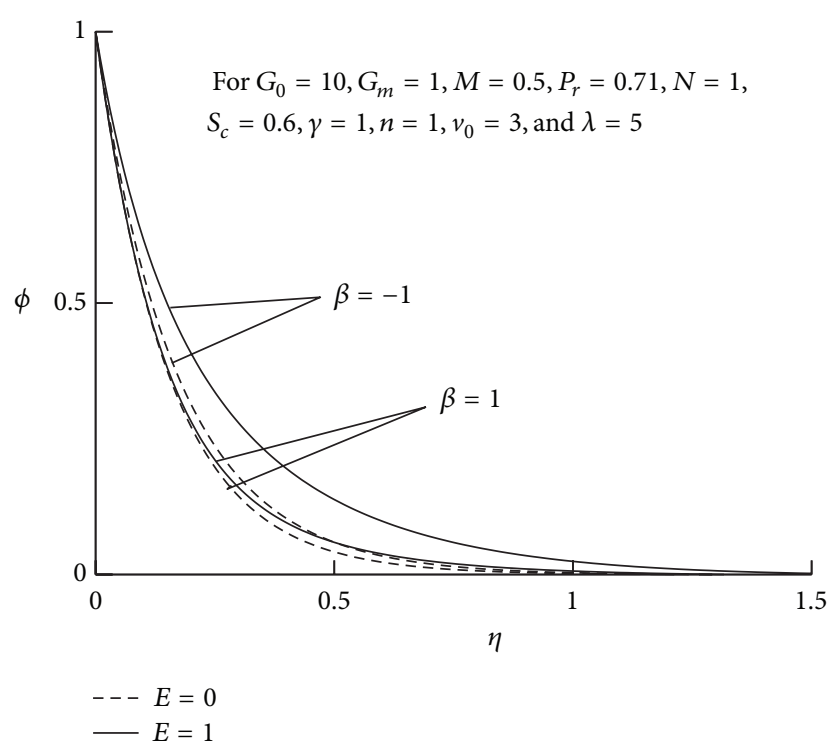

Figure 2: Effects of $\beta$ and $E$ on concentration profiles.

where $X=f^{\prime}(0), Y=\theta^{\prime}(0), Z=\phi^{\prime}(0)$, and $X, Y, Z$ subscripts indicate partial differentiation, for example, $f_{Y}^{\prime}=$ $\partial f^{\prime}\left(\eta_{\max }\right) / \partial \theta^{\prime}(0)$. The subscript $c$ indicates the value of the function at $\eta_{\max }$ to be determined from the trial integration.

Solutions of these equations in a least square sense require determining the minimum value of $E=\delta_{1}^{2}+$ $\delta_{2}^{2}+\delta_{3}^{2}+\delta_{4}^{2}+\delta_{5}^{2}+\delta_{6}^{2}$ with respect to $X, Y$, and $Z$. To solve $\Delta X, \Delta Y$, and $\Delta Z$, we require to differentiate $E$ with respect to $X, Y$ and $Z$, respectively. Thus adopting this numerical technique, a computer program was set up for the solutions of the basic nonlinear differential equations of our problem where the integration technique was adopted as the six-ordered Runge-Kutta method of integration. The results of this integration are then displayed graphically in

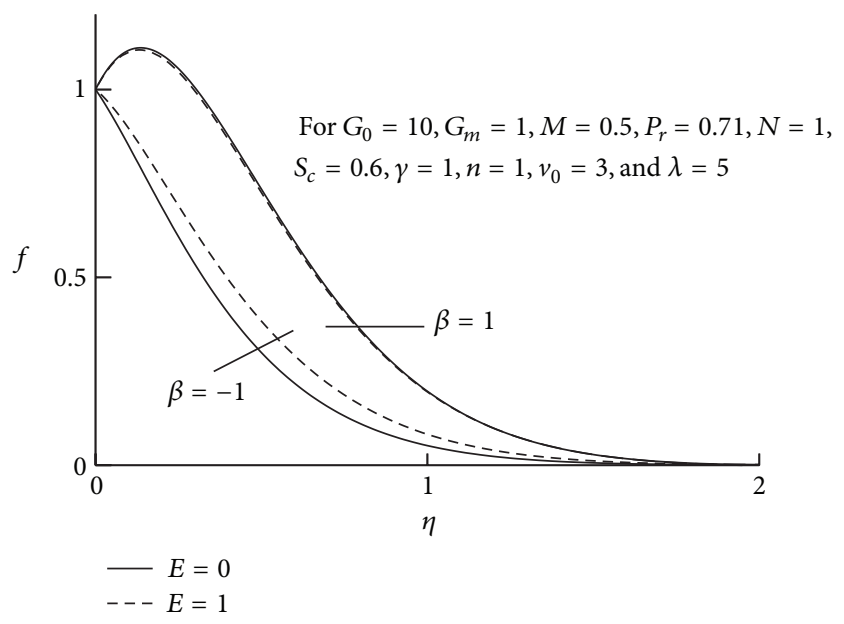

Figure 3: Effects of $\beta$ and $E$ on velocity profiles.

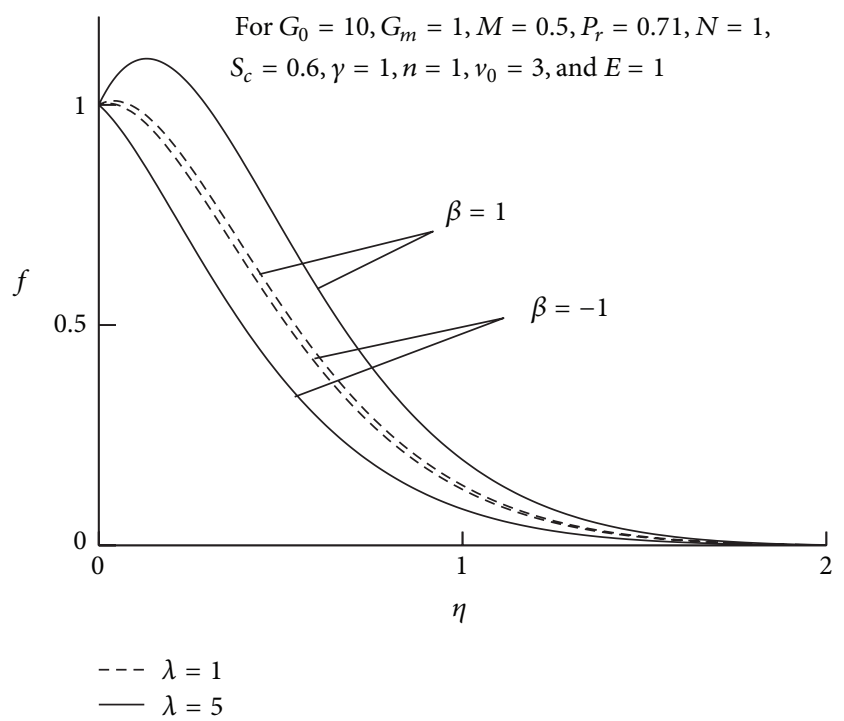

Figure 4: Effects of $\beta$ and $\lambda$ on velocity profiles.

the form of velocity, temperature, and concentration profiles in Figures 1-15. In the process of integration, the local skinfriction coefficient, the local rates of heat, and mass transfer to the surface, which are of chief physical interest, are also calculated out. The equation defining the wall skin friction is

$$
\tau=-\mu\left(\frac{\partial u}{\partial y}\right)_{y=0}=-\frac{\mu U_{0}}{\delta} f^{\prime}(0) .
$$

Hence the skin-friction coefficient is given by

$$
\frac{1}{2} C_{f}=\frac{\tau}{\rho U_{0}^{2}} \Longrightarrow \frac{1}{2} R_{e} C_{f}=-f^{\prime}(0),
$$

here, the Reynolds number $R_{e}=\rho U_{0} \delta / \mu$. 


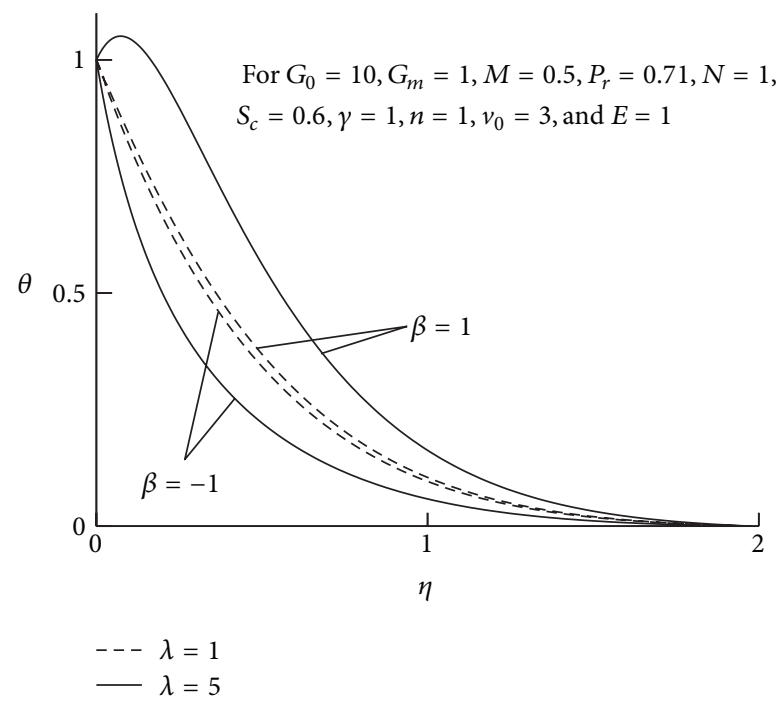

Figure 5: Effects of $\beta$ and $\lambda$ on temperature profiles.

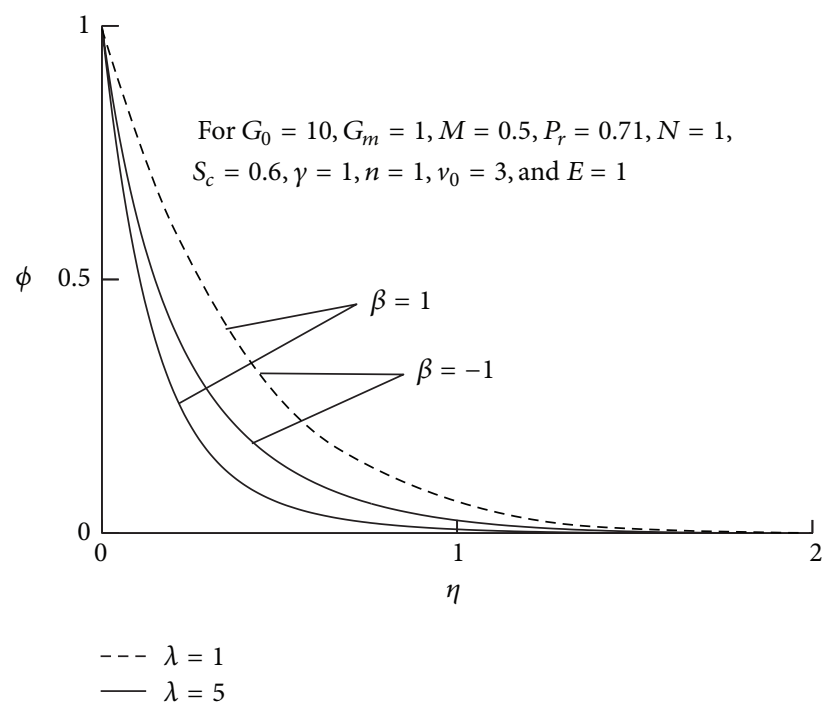

FIGURE 6: Effects of $\beta$ and $\lambda$ on concentration profiles.

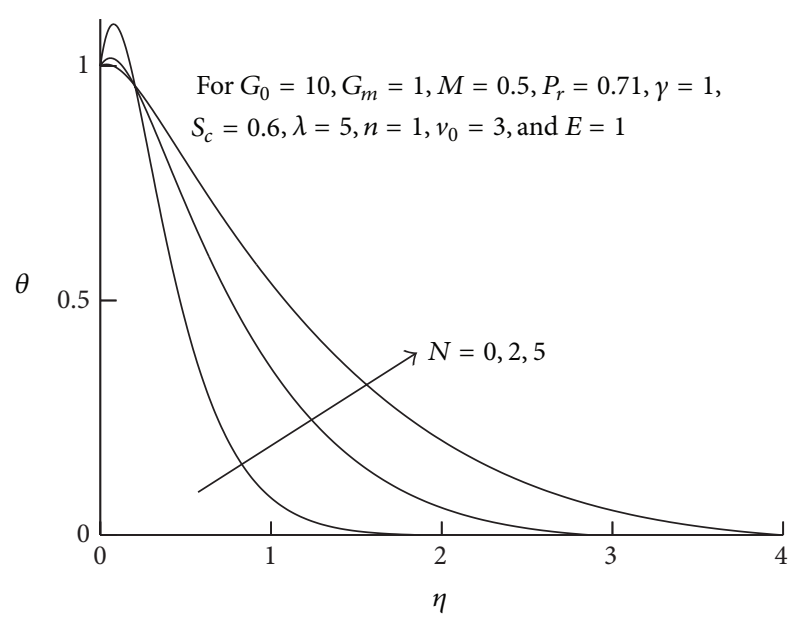

Figure 7: Effects of $N$ on temperature profiles.

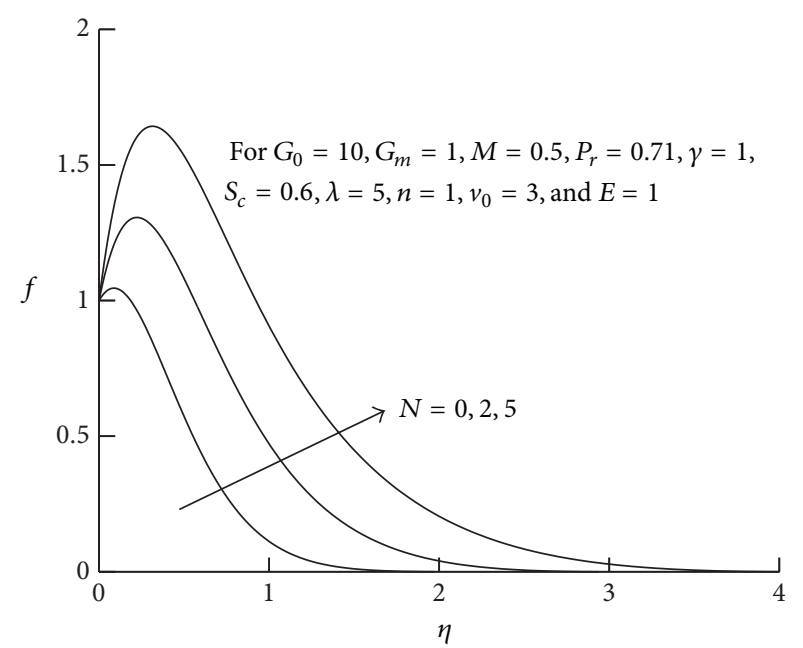

Figure 8: Effects of $N$ on velocity profiles.

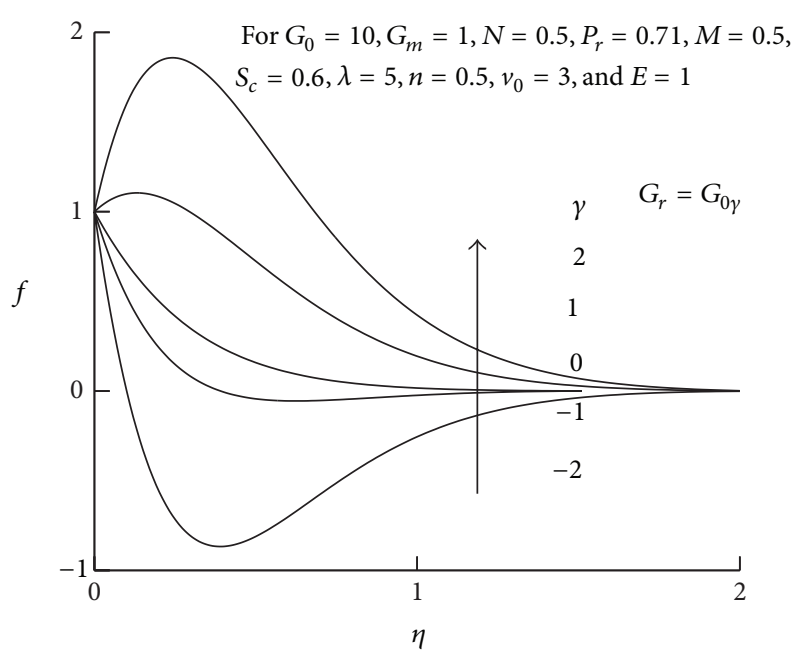

FIGURE 9: Effects of $\gamma$ on velocity profiles.

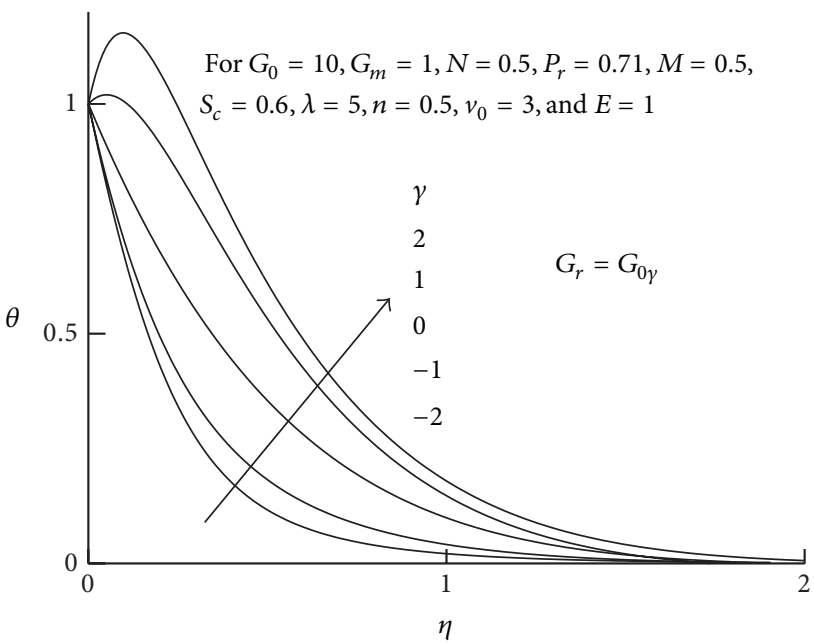

FIGURE 10: Effects of $\gamma$ on temperature profiles. 


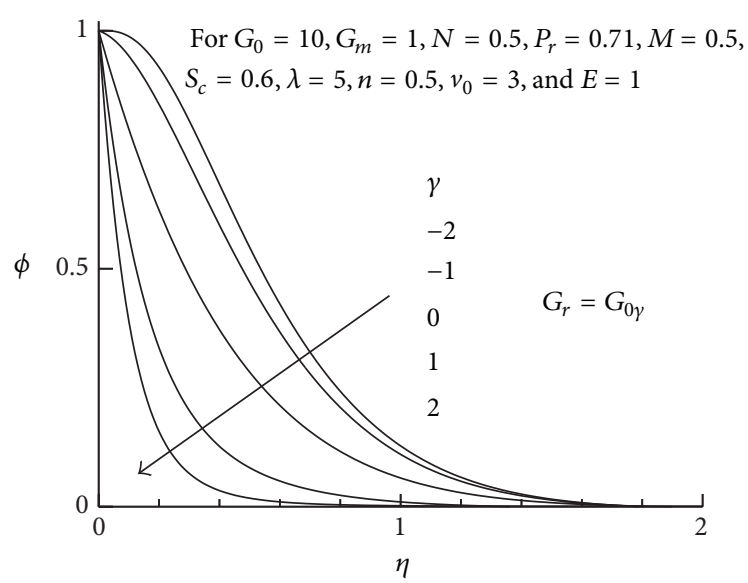

FIGURE 11: Effects of $\gamma$ on concentration profiles.

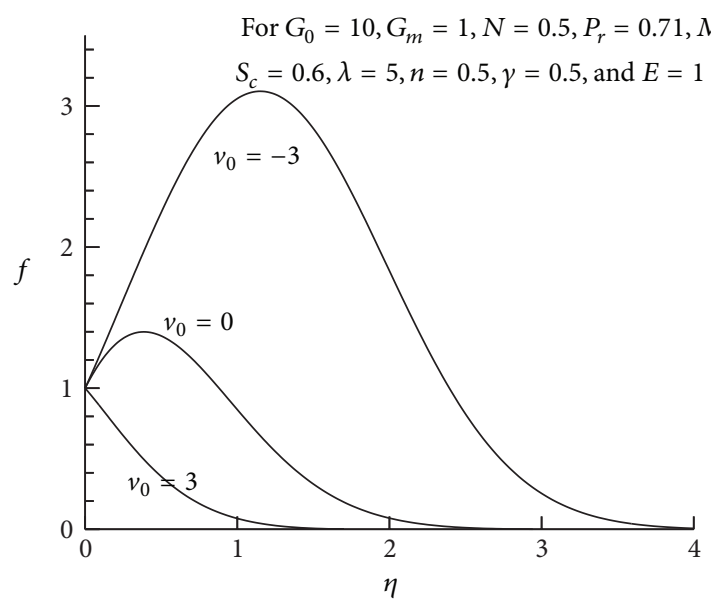

FigURE 12: Effects of $v_{0}$ on velocity profiles.

The heat flux $\left(q_{w}\right)$ and the mass flux $\left(M_{w}\right)$ at the wall are given by

$$
\begin{gathered}
q_{w}=-\kappa\left(\frac{\partial T}{\partial y}\right)_{y=0}=-\kappa \frac{\Delta T}{\delta} \theta^{\prime}(0), \\
M_{w}=-D_{M}\left(\frac{\partial C}{\partial y}\right)_{y=0}=-D_{M} \frac{\Delta C}{\delta} \phi^{\prime}(0) .
\end{gathered}
$$

Hence the Nusselt number $\left(N_{u}\right)$ and the Sherwood number $\left(S_{h}\right)$ are obtained as

$$
N_{u}=\frac{q_{w} \delta}{\kappa \Delta T}=-\theta^{\prime}(0), \quad S_{h}=\frac{M_{w} \delta}{D_{M} \Delta C}=-\phi^{\prime}(0) .
$$

These previous coefficients are then obtained from the procedure of the numerical computations and are sorted in Table 1.

\section{Results and Discussions}

The parameters entering into the fluid flow are Grashof number $G_{r}=G_{0} \gamma$, Solutal (modified) Grashof number $G_{m}$, suction parameter $v_{0}$, Prandtl number $P_{r}$, the nondimensional chemical reaction rate constant $\lambda^{2}$, Schmidt number

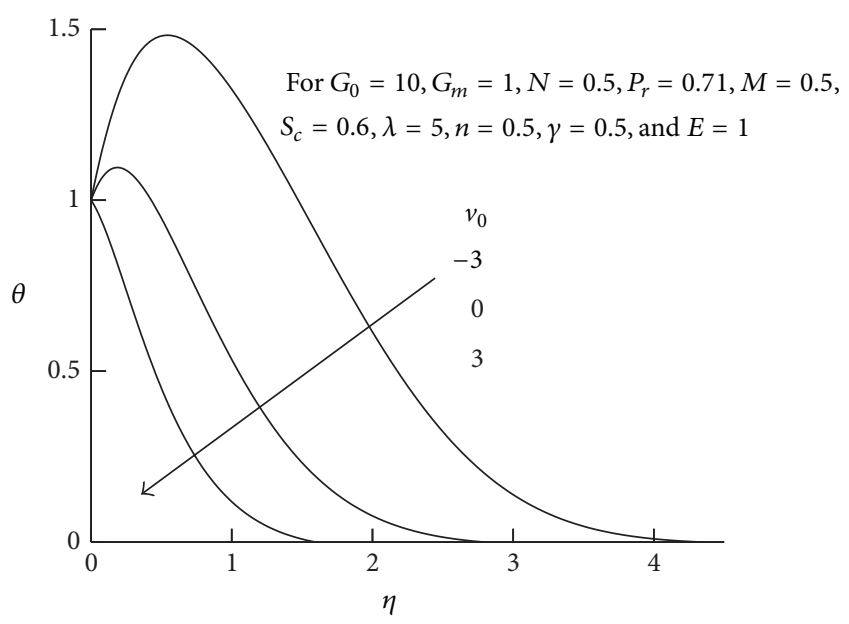

FIGURE 13: Effects of $v_{0}$ on temperature profiles.

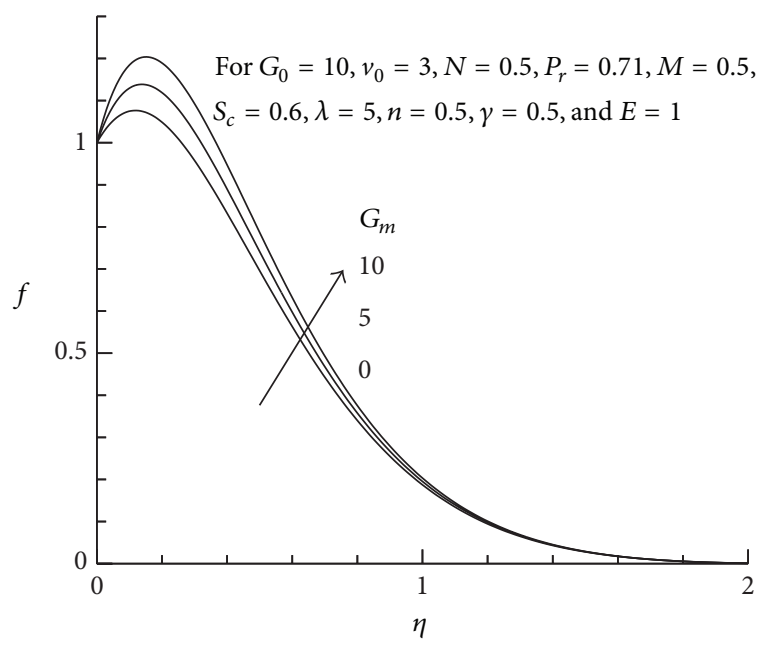

FIGURE 14: Effects of $G_{m}$ on velocity profiles.

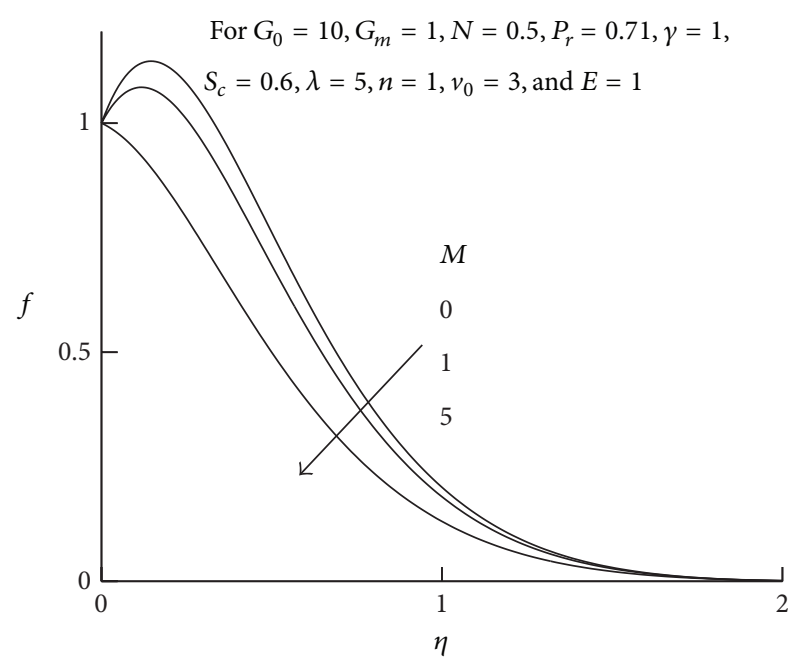

Figure 15: Effects of $M$ on velocity profiles. 


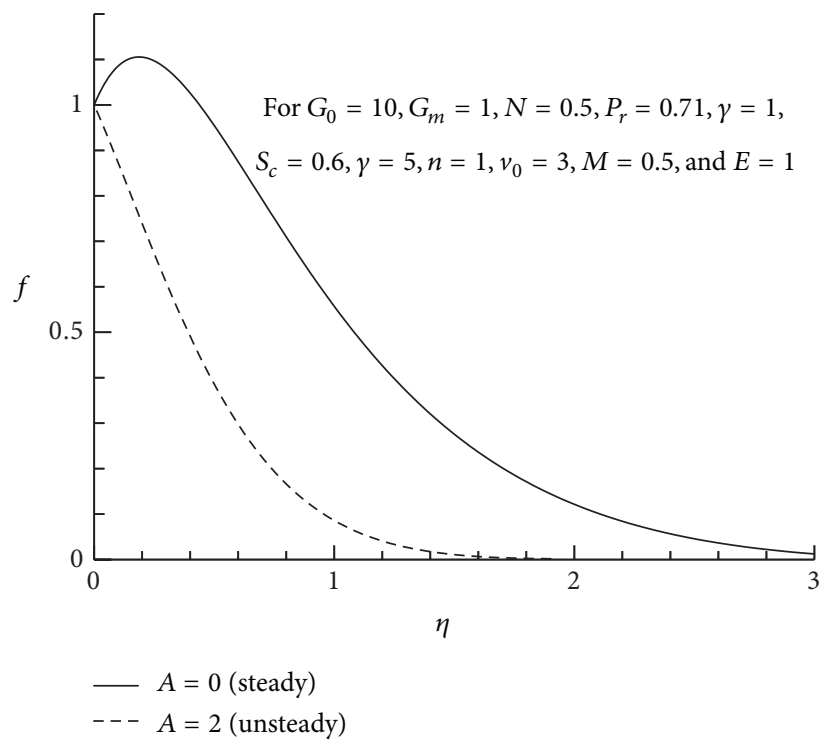

FIGURE 16: Effects of $A$ on velocity profiles.

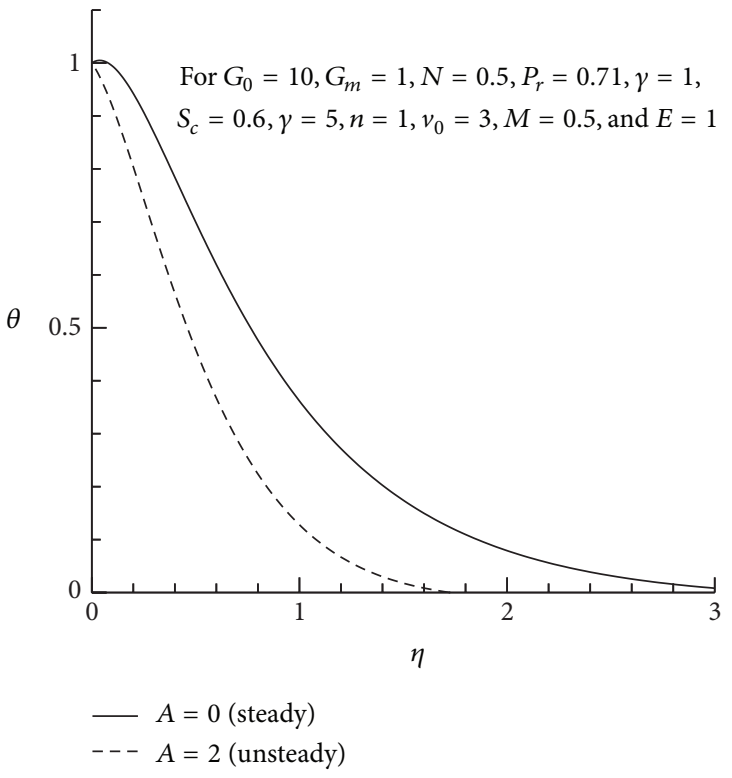

Figure 17: Effects of $A$ on temperature profiles.

$S_{c}$, the magnetic parameter $M$, the nondimensional activation energy $E$, the radiation parameter $N$, the exothermic/endothermic parameter $\beta$, and the temperature relative parameter $\gamma$.

It is, therefore, pertinent to inquire the effects of variation of each of them when the others are kept constant. The numerical results are thus presented in the form of velocity profiles, temperature profiles, and concentration profiles in Figures 1-14 for the different values of $G_{r}, G_{m}, \lambda, M, E, v_{0}, \beta$, and $\gamma$. The value of $\gamma$ is taken to be both positive and negative, since these values represent, respectively, cooling and heating of the plate.

The values of $G_{r}$ is taken to be large $\left(G_{r}=10\right.$, $G_{0}=10$, and $\gamma=1$ ), since the value corresponds to
TABLE 1: Effects on skin friction, heat transfer, and mass transfer coefficients. For $G_{0}=10, G_{m}=1, N=0.5, P_{r}=0.71, M=0.5, S_{c}=$ $0.6, \lambda=5, n=0.5, v_{0}=3, \gamma=0.5$, and $E=1$.

\begin{tabular}{cccc}
\hline & $-f^{\prime}(0)$ & $-\theta^{\prime}(0)$ & $-\phi^{\prime}(0)$ \\
\hline$E$ for $\beta=1$ & & & \\
0.0 & -1.65163 & -0.91802 & 5.78634 \\
0.5 & -1.60009 & -0.88980 & 5.75523 \\
1.0 & -1.54562 & -0.85343 & 5.70174 \\
$E$ for $\beta=-1$ & & & \\
0.0 & 1.30241 & 4.49966 & 5.55159 \\
0.5 & 0.98702 & 4.19573 & 5.21093 \\
1.0 & 0.63543 & 3.87806 & 4.81246 \\
$\lambda$ for $\beta=1$ & & & \\
1.0 & -0.43158 & 1.73298 & 2.42627 \\
2.0 & -0.63434 & 1.34699 & 2.91446 \\
5.0 & -1.54562 & -0.85343 & 5.70174 \\
$\lambda$ for $\beta=-1$ & & & \\
1.0 & -0.27903 & 1.98971 & 2.42088 \\
2.0 & -0.07554 & 2.32400 & 2.84424 \\
5.0 & 0.63543 & 3.87806 & 4.81246 \\
\hline
\end{tabular}

a cooling problem that is generally encountered in nuclear engineering in connection with the cooling of reactors. In air $\left(P_{r}=0.71\right)$ the diluting chemical species of most common interest have Schmidt number in the range from 0.6 to 0.75 . Therefore, the Schmidt number $S_{c}=0.6$ is considered. In particular, 0.6 corresponds to water vapor that represents a diffusing chemical species of most common interest in air. The values of the suction parameter $v_{0}$ are taken to be large. Apart from the figures and tables, the representative velocity, temperature, and concentration profiles and the values of the physically important parameters, that is, the local shear stress, the local rates of heat and mass transfer, are illustrated for uniform wall temperature and species concentration in Figures 1-17 and in Tables 1-2.

5.1. Effects of Activation Energy (E) on the Concentration, the Temperature, and the Velocity Profiles for Exothermicl Endothermic Chemical Reaction. In chemistry, activation energy is defined as the energy that must be overcome in order for a chemical reaction to occur. Activation energy may also be defined as the minimum energy required starting a chemical reaction. The activation energy of a reaction is usually denoted by $E_{a}$ and given in units of kilojoules per mole.

An exothermic reaction is a chemical reaction that releases energy in the form of light and heat. It is the opposite of an endothermic reaction. It gives out energy to its surroundings. The energy needed for the reaction to occur is less or greater than the total energy released for exothermic or endothermic reaction, respectively. Energy is obtained from chemical bonds. When bonds are broken, energy is required. When bonds are formed, energy is released. Each type of bond has specific bond energy. It can be predicted whether a chemical reaction will release or require heat by using bond energies. When there is more energy used to form 
TABLE 2: Effects on skin friction, heat transfer, and mass transfer coefficients. For $G_{0}=10, G_{m}=1, N=0.5, P_{r}=0.71, M=0.5, S_{c}=$ $0.6, \lambda=5, n=0.5, v_{0}=3, \gamma=0.5$, and $E=1$.

\begin{tabular}{|c|c|c|c|}
\hline & $-f^{\prime}(0)$ & $-\theta^{\prime}(0)$ & $-\phi^{\prime}(0)$ \\
\hline \multicolumn{4}{|l|}{$N$} \\
\hline 0.0 & -0.87260 & -1.44125 & 5.68996 \\
\hline 2.0 & -3.05961 & -0.30027 & 5.71624 \\
\hline 5.0 & -4.93466 & -0.04756 & 5.72770 \\
\hline \multicolumn{4}{|l|}{$M$} \\
\hline 0.0 & -1.85010 & -0.85309 & 5.70164 \\
\hline 2.0 & -0.75246 & -0.85443 & 5.70203 \\
\hline 5.0 & 0.46744 & -0.85628 & 5.70257 \\
\hline \multicolumn{4}{|l|}{$\gamma$} \\
\hline-2.00000 & 7.32171 & 3.65294 & 0.07835 \\
\hline-1.00000 & 5.66728 & 3.48636 & 0.26098 \\
\hline 0.00000 & 3.31180 & 1.88820 & 2.28076 \\
\hline 1.00000 & -1.54562 & -0.85343 & 5.70174 \\
\hline 2.00000 & -7.85616 & -3.67839 & 9.25776 \\
\hline \multicolumn{4}{|l|}{$A$} \\
\hline 0.00000 & -1.27274 & -0.26974 & 3.97243 \\
\hline 2.00000 & 1.20419 & 0.56519 & 3.91549 \\
\hline
\end{tabular}

the bonds than to break the bonds, heat is given off. This is known as an exothermic reaction. When a reaction requires an input or output of energy, it is known as an exothermic or endothermic reaction.

Effects of activation energy $(E)$ and exothermic parameter $(\beta)$ on the temperature, the concentration and velocity profiles are shown in Figure 1 to Figure 3, respectively. $\beta=1$ and $\beta=-1$ represent exothermic and endothermic chemical reactions, respectively. Figure 1 shows that a small decreasing effect of temperature profile is found for increasing values of $E$ for exothermic reaction $(\beta=1)$, but mark opposite effects are found for endothermic reaction in Figure 1. That is the temperature profile increases for increasing values of $E$ for endothermic reaction $\beta=-1$. From (1) we observe that chemical reaction rate $(K)$ decreases with the increasing values of activation energy $\left(E_{a}\right)$. We also observe from (20) that increase in activation energy $(E)$ leads to decrease $\lambda^{2} \exp (-E / \theta)$ as well as to increase in the concentration profiles shown in Figure 2. Small and reported effects are found for $\beta=1$ and $\beta=-1$, respectively. The parameter $E$ does not enter directly into the momentum equation, but its influence comes through the mass and energy equations. Figure 3 shows the variation of the velocity profiles for different values of $E$. From this figure it has been observed that the velocity profile mark increases with the increasing values of $E$ for endothermic chemical reaction. But negligible effects are found for exothermic reaction.

5.2. Effects of $\lambda$ on the Concentration, the Temperature, and the Velocity Profiles for Exothermic/Endothermic Reaction. Considering chemical reaction rate constant $\lambda^{2}$ is always positive. Figures 4-6 represent the effect of chemical rate constant $\lambda$ on the velocity, the temperature, and the concentration profiles, respectively.

We observe from Figures 4 and 5 that velocity and temperature profiles increase with the increasing values of $\lambda$ for exothermic reaction, but opposite effects are found in these figures for endothermic reaction. It is observed from (1) that increasing temperature frequently that causes a marked increase in the rate of reactions is shown in Figure 4. As the temperature of the system increases, the number of molecules that carry enough energy to react when they collide also increases. Therefore, the rate of reaction increases with temperature. As a rule, the rate of a reaction doubles for every $10^{\circ} \mathrm{C}$ increase in the temperature of the system.

Last part of (20) shows that $\lambda^{2} \exp (-E / \theta)$ increases with the increasing values of $\lambda$. We also observe from this equation that increase in $\lambda^{2} \exp (-E / \theta)$ means that increase in $\lambda$ leads to the decrease in the concentration profiles. This is in great agreement with Figure 6 for both cases $\beta= \pm 1$. It is also observed from this figure that for exothermic reaction the mass boundary layer is close to the plate other than endothermic reaction.

\subsection{Effects of Radiation Parameter $N$ on Temperature and} Velocity Profiles. The effects of radiation parameter $N$ on the temperature and the velocity profiles are shown in Figures 7 and 8. From Figure 7, it can be seen that an increase in the values of $N$ leads to a decrease in the values of temperature profiles within the thermal boundary layers $\eta<0.22$, while outside $\eta>0.22$, the temperature profile gradually increases with the increase of the radiation parameter $N$. It is appear from Figure 8 that when $N=0$, that is, without the radiation, the velocity profile shows its usual trend of gradually decay. As radiation becomes larger the profiles overshoot the uniform velocity close to the boundary.

5.4. Effects of $\gamma$ on the Velocity, Temperature, and Concentration Profiles. The value of $\gamma=\Delta T / T_{\infty}$ is taken to be both positive and negative, since these values represent, respectively, cooling and heating of the plate. The effects of temperature relative parameter on velocity, temperature, and concentration profiles are shown in Figures 9-11.

The velocity profiles generated due to impulsive motion of the plate is plotted in Figure 9 for both cooling $(\gamma>0)$ and heating $(\gamma<0)$ of the plate keeping other parameters fixed $\left(G_{0}=10, G_{m}=1.0, M=E_{c}=0.5, P_{r}=0.71, S_{c}=0.6\right.$, $\lambda=5, v_{0}=3.0, E=1.0$, and $\left.n=1\right)$. In Figure 9, velocity profiles are shown for different values of $\gamma$. We observe that velocity increases with increasing values of $\gamma$ for the cooling of the plate. From this figure it is also observed that the negative increase in the temperature relative parameter leads to the decrease in the velocity field. That is, for heating of the plate (Figure 9), the effects of the $\gamma$ on the velocity field have also opposite effects, as compared to the cooling of the plate. Figure 10 shows the effects of temperature relative parameter $\gamma$ on the temperature profiles. It has been observed from this figure that for heating plate the temperature profile shows its usual trend of gradually decay, and the thermal boundary layer is close to the plate. But for cooling plate 
that is temperature relative parameter $\gamma$ becomes larger, the profiles overshoot the uniform temperature close to the thermal boundary. Opposite effects of temperature profile are found for concentration profiles shown in Figure 11.

5.5. Effects of Suction/Injection $\left(v_{0}\right)$ on the Velocity and the Temperature Profiles. The effects of suction and injection $\left(v_{0}\right)$ for $G_{0}=10, G_{m}=1.0, M=E_{c}=0.5, P_{r}=0.71, S_{c}=0.6$, $\lambda=5, \gamma=0.5, E=1.0$, and $n=1$ on the velocity profiles and temperature profiles are shown, respectively, in Figures 12 and 13. For strong suction $\left(v_{0}>0\right)$, the velocity and the temperature decay rapidly away from the surface. The fact that suction stabilizes the boundary layer is also apparent from these figures. As for the injection $\left(v_{0}<0\right)$, from Figures 12 and 13 it is observed that the boundary layer is increasingly blown away from the plate to form an interlayer between the injection and the outer flow regions.

5.6. Effects of $G_{m}$ and $M$ on the Velocity Profiles. The effects of Solutal Grashof number $G_{m}$ and magnetic interaction parameter $M$ on velocity profiles are shown in Figures 14 and 15 , respectively. Solutal Grashof number $G_{m}>0$ corresponds that the chemical species concentration in the free stream region is less than the concentration at the boundary surface. Figure 14 presents the effects of Solutal Grashof number $G_{m}$ on the velocity profiles. It is observed that the velocity profile increases with the increasing values of Solutal Grashof number $G_{m}$.

Imposition of a magnetic field to an electrically conducting fluid creates a drag like force called Lorentz force. The force has the tendency to slow down the flow around the plate at the expense of increasing its temperature. This is depicted by decreases in velocity profiles as magnetic parameter $M$ increases as shown in Figure 15.

5.7. Effects of $A$ on the Velocity and the Temperature Profiles. Here $A=0$ and $A \neq 0$ represent steady and unsteady flows, respectively. The effects of $A$ on velocity and temperature profiles are shown in Figures 16 and 17, respectively. For unsteady flow $(A \neq 0)$ both figures show that the profiles rapidly decay and close to the plate. But for steady flow $(A=$ 0 ) the profiles overshoot the uniform velocity/temperature close to the boundary.

5.8. The Skin-Friction, the Heat Transfer, and the Mass Transfer Coefficients. The skin-friction, the heat transfer, and the mass transfer coefficients are tabulated in Tables 1 and 2 for different values of $E, \beta, \lambda, N, M, \gamma$, and $A$. We observe from Table 1 that the skin-friction coefficient $\left(-f^{\prime}(0)\right)$ and the Nusselt number $N_{u}\left(=-\theta^{\prime}(0)\right)$ increase for increasing values of dimensionless activation parameter $E$ for exothermic chemical reaction, but opposite actions are found for endothermic reaction. That is for endothermic reaction, it is found that both shearing stress and heat transfer coefficients decrease for increasing values of $E$. For both cases exothermic/endothermic reactions, the mass transfer coefficient $\left(=-\phi^{\prime}(0)\right)$ decreases for increasing values of $E$. We also observe from Table 1 that the skin-friction coefficient

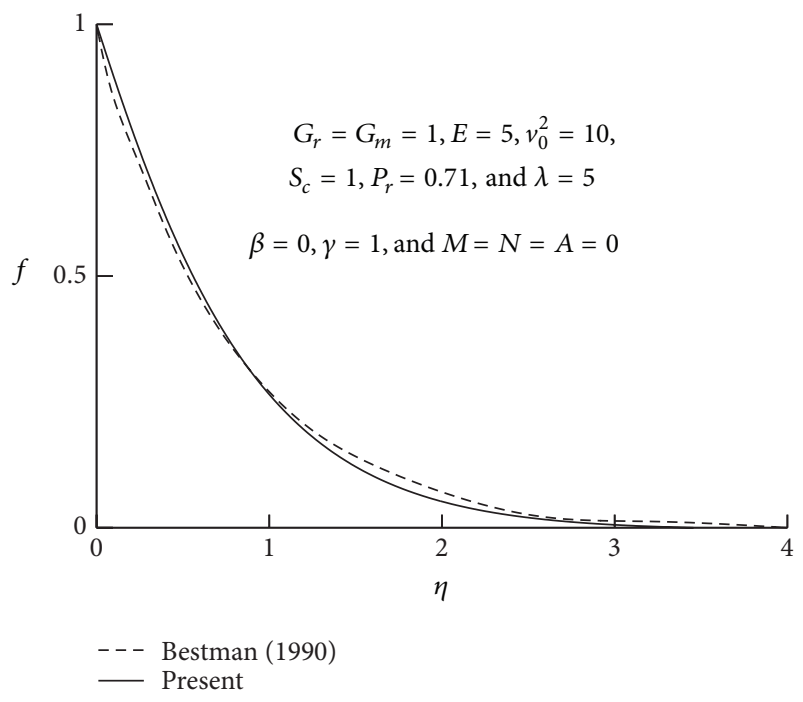

Figure 18: Comparison of our calculated velocity profile and the velocity profile of Bestman [7].

$\left(-f^{\prime}(0)\right)$ and the Nusselt number $N_{u}\left(=-\theta^{\prime}(0)\right)$ decrease for increasing values of dimensionless reaction rate constant $\lambda$ for exothermic chemical reaction, but opposite effects are found for endothermic reaction. That is for endothermic reaction, it is found that both shearing stress and heat transfer coefficients increase for increasing values of $\lambda$. For both cases exothermic/endothermic reactions, the mass transfer coefficient $\left(=-\phi^{\prime}(0)\right)$ remarkably increases for increasing values of $\lambda$. From Table 2 it has been observed that the skin-friction coefficient remarkably decreases and Nusselt number remarkable increases for increasing values of radiation parameter $N$. The skin-friction coefficient increases for increasing values of magnetic parameter $M$. From Table 2 we also found that skin friction and heat transfer coefficients decrease, but mass transfer coefficient increases for increasing values of temperature relative parameter $\gamma$.

5.9. Comparison between Our Numerical Result and the Analytical Result of Bestman [7]. Bestman studied steady natural convective boundary layer flow with large suction. He solved his problem analytically by employing the perturbation technique proposed by Singh and Dikshit [8]. In our present work, take $A=0$ in (16) for considering steady flow. The values of the suction parameter $v_{0}^{2}=10$ is taken to see the effects of large suction. $G_{r}=G_{m}=1.0, \gamma=1$, $M=N=0, \lambda=5, E=5$, and $n=1$ are also chosen with a view to compare our numerical results with the analytical results of Bestman [7]. The comparison of velocity profiles as seen in Figure 18 highlights the validity of the numerical computations adapted in the present investigation.

\section{Conclusions}

In this paper, we investigate the effects of chemical reaction rate and Arrhenius activation energy on an unsteady MHD 
natural convection heat and mass transfer boundary layer flow past a flat porous plate in presence of thermal radiation.

The Nachtsheim and Swigert [18] iteration technique based on sixth-order Runge-Kutta and Shooting method has been employed to complete the integration of the resulting solutions.

The following conclusions can be drawn as a result of the computations.

(1) Velocity increases with increasing values of $\gamma$ for the cooling of the plate, and the negative increase in the temperature relative parameter $\gamma$ leads to the decrease in the velocity field. That is, for heating of the plate the effects of the temperature relative parameter $\gamma$ on the velocity field have also opposite effects, as compared to the cooling of the plate.

(2) Solutal Grashof number $G_{m}>0$ corresponds that the chemical species concentration in the free stream region is less than the concentration at the boundary surface. It is observed that the velocity profile increases with the increasing values of Solutal Grashof number $G_{m}$.

(3) Increase in $\lambda$ leads to increase in the velocity, and temperature profiles for exothermic reaction but opposite effects are found for endothermic reaction. For $\beta= \pm 1$ increase in $\lambda$ leads to the decrease in the concentration profiles, but for exothermic reaction, the mass boundary layer is close to the plate other than endothermic reaction.

(4) The velocity profile mark increases with the increasing values of $E$ for endothermic chemical reaction. But negligible effect is found for exothermic reaction. Temperature decreases for increasing values of $E$ for exothermic reaction, but opposite effects are found for endothermic reaction. Activation energy $(E)$ leads to increase in the concentration profiles, but small and reported effects are found for $\beta=1$ and $\beta=-1$, respectively.

(5) For strong suction $\left(v_{0}>0\right)$, the velocity, the temperature, and the concentration profiles decay rapidly away from the surface. As for the injection $\left(v_{0}<0\right)$, it is observed that the boundary layer is increasingly blown away from the plate to form an interlayer between the injection and the outer flow regions.

(6) Imposition of a magnetic field to an electrically conducting fluid creates a drag like force called Lorentz force. The force has the tendency to slow down the flow around the plate at the expense of increasing its temperature. This is depicted by decreases in velocity profiles as magnetic parameter $M$ increases

(7) An increase in the values of $N$ leads to a decrease in the values of temperature profiles within the thermal boundary layers $\eta<0.22$, while outside $\eta>0.22$ the temperature profile gradually increases with the increase of the radiation parameter $N$.

(8) For unsteady flow $(A \neq 0)$ the velocity and the temperature profiles rapidly decay and close to the plate.
But for steady flow $(A=0)$ the profiles overshoot the uniform velocity/temperature close to the boundary.

\section{Nomenclature}

$(u, v)$ : Components of velocity field

$c_{p}$ : Specific heat at constant pressure

$N_{u}$ : Nusselt number

$P_{r}$ : Prandtl number

$Q_{0}$ : Heat generation/absorption coefficient

$S_{h}$ : Sherwood number

$T: \quad$ Temperature of the flow field

$T_{\infty}$ : Temperature of the fluid at infinity

$T_{w}$ : Temperature at the plate

$f: \quad$ Dimensionless similarity functions

$E_{a}: \quad$ The activation energy

$k$ : The Boltzmann constant

$S_{c}: \quad$ Schmidt number

$E$ : The nondimensional activation energy

$G_{r}: \quad$ Grashof number

$G_{m}$ : Modified (Solutal) Grashof number.

\section{Greek Symbols}

$\theta: \quad$ Dimensionless temperature

$\phi: \quad$ Dimensionless concentration

$\eta$ : $\quad$ Dimensionless similarity variable

$\delta: \quad$ Scale factor

$v: \quad$ Kinematic viscosity

$\rho: \quad$ Density of the fluid

$\kappa: \quad$ Thermal conductivity

$\tau: \quad$ Shear stress,

$\mu$ : $\quad$ Fluid viscosity

$\lambda^{2}$ : Dimensionless chemical reaction rate constant

$\beta$ and $\beta^{*}$ : The coefficients of volume expansions for temperature and concentration, respectively

$\gamma: \quad$ The dimensionless heat generation/absorption coefficient.

\section{References}

[1] M. Tencer, J. S. Moss, and T. Zapach, "Arrhenius average temperature: the effective temperature for non-fatigue wearout and long term reliability in variable thermal conditions and climates," IEEE Transactions on Components and Packaging Technologies, vol. 27, no. 3, pp. 602-607, 2004.

[2] C. Truesdell, "Sulle basi della thermomeccanica," Rendiconti Lincei, vol. 22, no. 8, pp. 33-38, 1957.

[3] N. Mills, "Incompressible mixtures of newtonian fluids," International Journal of Engineering Science, vol. 4, no. 2, pp. 97-112, 1966.

[4] C. E. Beevers and R. E. Craine, "On the determination of response functions for a binary mixture of incompressible newtonian fluids," International Journal of Engineering Science, vol. 20, no. 6, pp. 737-745, 1982. 
[5] A. Al-Sharif, K. Chamniprasart, K. R. Rajagopal, and A. Z. Szeri, "Lubrication with binary mixtures: liquid-liquid emulsion," Journal of Tribology, vol. 115, no. 1, pp. 46-55, 1993.

[6] S. H. Wang, A. Al-Sharif, K. R. Rajagopal, and A. Z. Szeri, "Lubrication with binary mixtures: liquid-liquid emulsion in an EHL conjunction," Journal of Tribology, vol. 115, no. 3, pp. 515$522,1993$.

[7] A. R. Bestman, "Natural convection boundary layer with suction and mass transfer in a porous medium," International Journal of Energy Research, vol. 14, no. 4, pp. 389-396, 1990.

[8] A. K. Singh and C. K. Dikshit, "Hydromagnetic flow past a continuously moving semi-infinite plate for large suction," Astrophysics and Space Science, vol. 148, no. 2, pp. 249-256, 1988.

[9] A. R. Bestman, "Radiative heat transfer to flow of a combustible mixture in a vertical pipe," International Journal of Energy Research, vol. 15, no. 3, pp. 179-184, 1991.

[10] M. A. Alabraba, A. R. Bestman, and A. Ogulu, "Laminar convection in binary mixture of hydromagnetic flow with radiative heat transfer, I," Astrophysics and Space Science, vol. 195, no. 2, pp. 431-439, 1992.

[11] R. Kandasamy, K. Periasamy, and K. K. S. Prabhu, "Effects of chemical reaction, heat and mass transfer along a wedge with heat source and concentration in the presence of suction or injection," International Journal of Heat and Mass Transfer, vol. 48, no. 7, pp. 1388-1394, 2005.

[12] O. D. Makinde, P. O. Olanrewaju, and W. M. Charles, "Unsteady convection with chemical reaction and radiative heat transfer past a flat porous plate moving through a binary mixture," Africka Matematika, vol. 22, no. 1, pp. 65-78, 2011.

[13] O. D. Makinde and P. O. Olanrewaju, "Unsteady mixed convection with Soret and Dufour effects past a porous plate moving through a binary mixture of chemically reacting fluid," Chemical Engineering Communications, vol. 198, no. 7, pp. 920-938, 2011.

[14] Kh. Abdul Maleque, "Unsteady natural convection boundary layer flow with mass transfer and a binary chemical reaction," British Journal of Applied Science and Technology (Sciencedomain International), vol. 3, no. 1, pp. 131-149, 2013.

[15] Kh. Abdul Maleque, "Unsteady natural convection boundary layer heat and mass transfer flow with exothermic chemical reactions," Journal of Pure and Applied Mathematics (Advances and Applications), vol. 9, no. 1, pp. 17-41, 2013.

[16] Kh. Abdul Maleque, "Effects of binary chemical reaction and activation energy on MHD boundary layer heat and mass transfer flow with viscous dissipation and heat generation/absorption," ISRN Thermodynamics, vol. 2013, Article ID 284637, 9 pages, 2013.

[17] Kh. Abdul Maleque, "Effects of combined temperature- and depth-dependent viscosity and hall current on an unsteady MHD laminar convective flow due to a rotating disk," Chemical Engineering Communications, vol. 197, no. 4, pp. 506-521, 2010.

[18] P. R. Nachtsheim and P. Swigert, "Satisfaction of asymptotic boundary conditions in numerical solution of system of nonlinear of boundary layer type," NASA TN-D3004, 1965. 

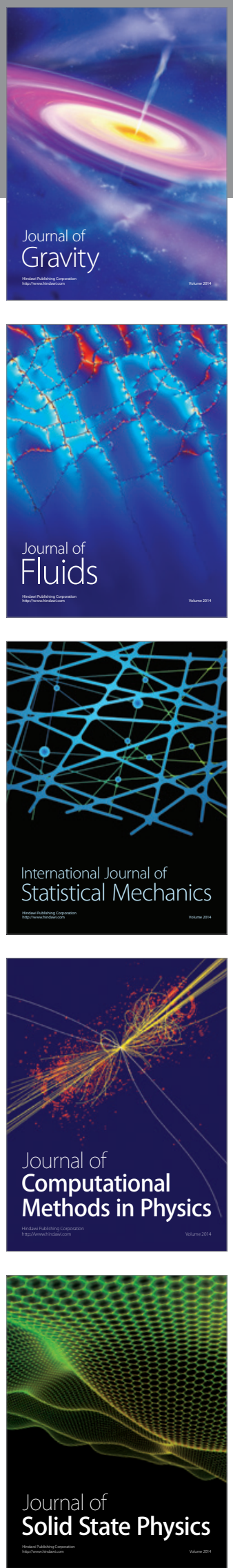

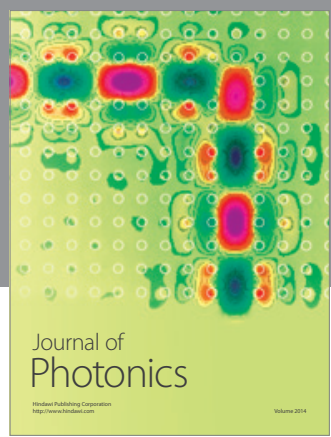

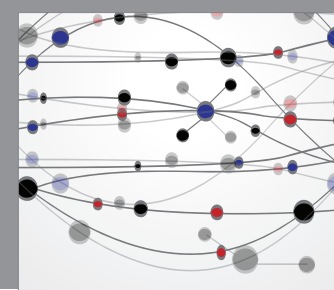

The Scientific World Journal

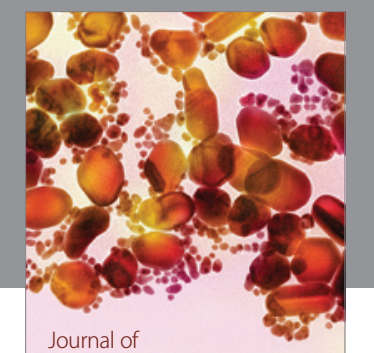

Soft Matter
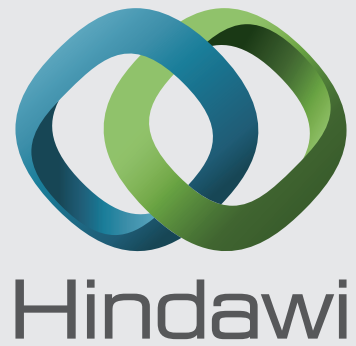

Submit your manuscripts at

http://www.hindawi.com
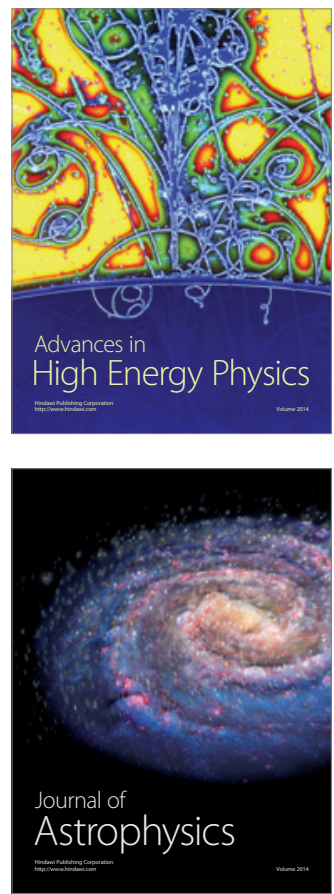
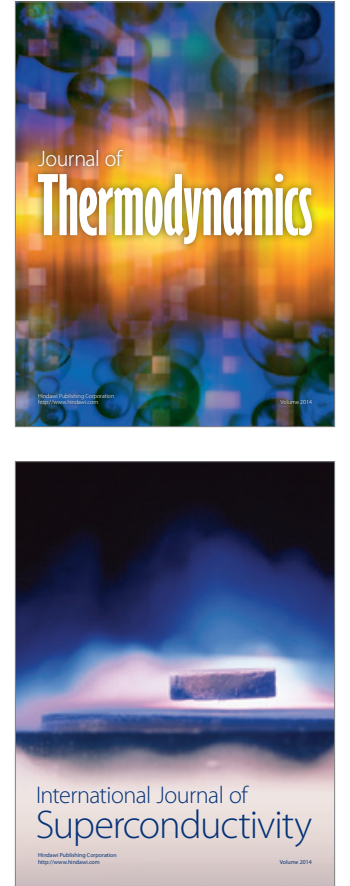
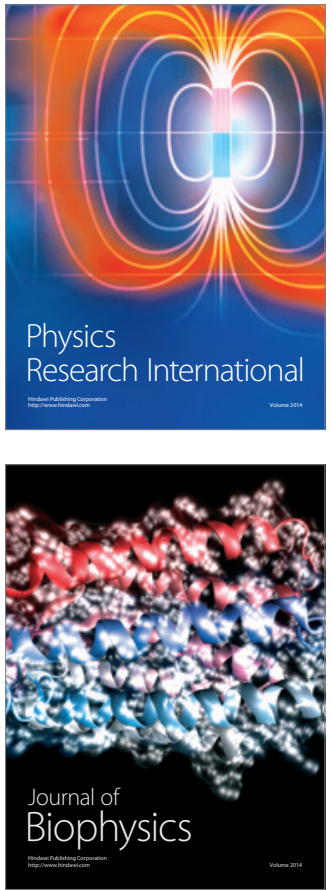
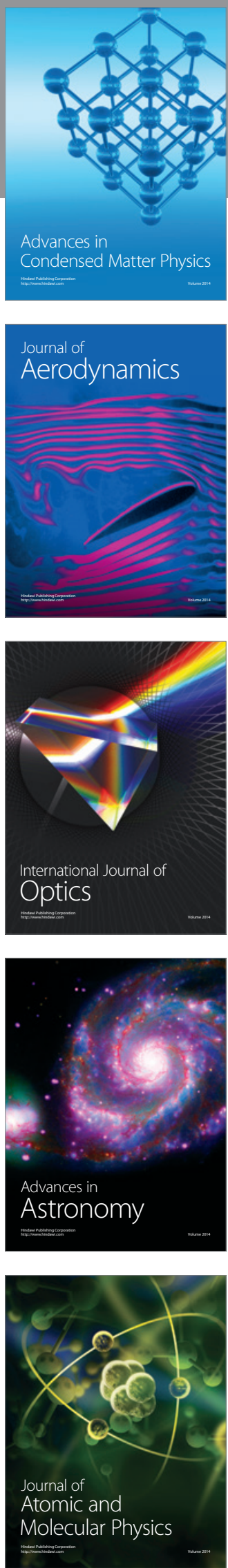